\title{
The Peak Value of Carbon Emissions in the Beijing-Tianjin-Hebei Region Based on the STIRPAT Model and Scenario Design
}

\author{
Lei Wen, Yanjun Liu* \\ Department of Economics and Management, North China Electric Power University, \\ Baoding, Hebei, 071003, China
}

Received: 30 July 2015

Accepted: 3 January 2016

\begin{abstract}
The main objective of this paper was seeking suitable scenarios for the Beijing-Tianjin-Hebei region, where both socio-economic development and low-carbon targets would be achieved. Potential driven factors of carbon emissions, including population, affluence, urbanization level, technology level, industrial construction, and energy consumption construction were selected to build an extended stochastic impacts by regression on population, affluence, and technology (STIRPAT) model, where ridge regression was applied to ensure its stability. The STIRPAT model showed the significance of each independent variable, which was the foundation of $\mathrm{CO}_{2}$ emissions' prediction. Furthermore, eight scenarios were established to explore the possible carbon footprints and the maximum of $\mathrm{CO}_{2}$ in the period from 2013 to 2050. This paper finally proposed the strategies that can be applied to reduce future carbon emissions in the Beijing-Tianjin-Hebei region. Applying reasonable policies about improvement of technological level, and adjustment of industry and energy consumption structures is a critical factor for the control of $\mathrm{CO}_{2}$ emissions.
\end{abstract}

Keywords: carbon emissions, STIRPAT model, ridge regression, scenario analysis

\section{Introduction}

"Greenhouse effect" was first proposed by Swedish scientist Svante Ahrrenius, and it was proved that the Greenhouse effect is attributed largely to carbon emissions as the principal influence on the global socioeconomic system and ecosystem $[1,2]$. Consequently, the control of $\mathrm{CO}_{2}$ emissions has attracted increasing attention due to its important impact on climate change mitigation.

China has been the largest $\mathrm{CO}_{2}$ emitter in the world over the past six years, accounting for more than $25 \%$

*e-mail: fastgu@163.com of the total emissions all around the world in 2009 [3] and covering $27 \%$ of global emissions in 2012 [4]. The Beijing-Tianjin-Hebei region, as one of new economic support zones in China, plays an important role in the development of China. Since 2000, the GDP in this region has grown at an average of 15.8 percent per annum, population has doubled, and urbanization level has reached 58\%. Unfortunately, the $\mathrm{CO}_{2}$ emissions have been increasing over time. $\mathrm{CO}_{2}$ emissions in the BeijingTianjin-Hebei region increased from 357.87 million to 803.19 million tons with an average rise rate of $7 \%$ during 2000-12. Therefore, seeking a suitable mode to satisfy both development demand and low carbon emissions is 
imperative for the region. The problem of carbon emissions should be respond for its environmental sustainability.

At present, the conversion factors of emissions and the peak of $\mathrm{CO}_{2}$ emissions have been researched by several studies. The stochastic impacts by regression on population, affluence, and technology (STIRPAT) model is one of the most popular measures used in studies about $\mathrm{CO}_{2}$ emissions. STIRPAT was proposed by Dietz and Rosa $[5,6]$ as an improvement of the IPAT model. Since then, a lot of studies were undertaken to research the relationship between emissions and its possible driven factors based on this model.

The STIRPAT model can be rewritten as a linear model through a (natural) logarithmic transformation. The parameters of the linear model were usually obtained by ordinary least square (OLS) regression, whereas the regression coefficients of each variable obtained by the OLS would be very unstable as the impact of multicollinearity among independent variables. The partial least square (PLS) method and ridge regression can be used to avoid this adverse effect, which was proposed respectively by Wold et al. [7] and by Hoerl and Kennard [8].

The novelty of this paper lies in its studies of future carbon footprints and maximum emissions under different scenarios in the Beijing-Tianjin-Hebei region. These scenarios would be set based on an improved STIRPAT model, which is established through ridge regression according to analysis of regional current situations to help local governments figure out the main point to ensure the decrease of $\mathrm{CO}_{2}$ emissions before 2050. Moreover, the distinctions among these scenarios can be a guide to testify to the best development mode and the implications of policies toward low-carbon economies.

The rest of the article is organized as follows:

- Section 2 provides a briefly introduce of the existing literature.

- Section 3 presents the main models used: measurement of $\mathrm{CO}_{2}$ emissions, the STIRPAT model, ridge regression.

- Section 4 performs main empirical results.

- Section 5 designs eight scenarios for the BeijingTianjin-Hebei region and predicts the variations of driven variables in each scenario.

- The development strategies for low $\mathrm{CO}_{2}$ emissions are listed in Section 6.

- Finally, Section 5 concludes the article.

\section{Literature Review}

At present, the conversion factors of emissions and the peak of $\mathrm{CO}_{2}$ emissions have been researched by several studies. Kenny and Gray described the curve of $\mathrm{CO}_{2}$ emissions in Ireland by five driven factors, which were researched through six different models [9]. The concept "peak of energy consumption" was proposed by Sun in 1999 [10]. In addition, more attention has been paid to the trend of China's prospective $\mathrm{CO}_{2}$ emissions as well as potential capability to reduce carbon emissions. China's $\mathrm{CO}_{2}$ emissions are expected to rise rapidly in the coming decade according to trend analysis [11]. China's $\mathrm{CO}_{2}$ emissions will increase up to 2020, and the potential for reduction is great [12]. China's Energy Research Institute (ERI) predicted the energy demand of China and Carbon Emissions Scenarios Analysis in 2050 using the IPACSGM model, which tries to correlate the output of main energy-intensive products with the sector's total economic consumption [13]. The Tyndall Center listed several possible states for China in 2050 involving its economic and social development under the fixed carbon budget [14]. Besides, although there were great discrepancies among their results, LBNL, McKinsey, and UNDP adopted the top-down approach and set different scenarios that were all China-based models without specific global targets to explore China's potential $\mathrm{CO}_{2}$ emissions trajectories to $2050[2,15,16]$.

In the 1970s Ehrlich and Holden first put forward a model to analyze the impacts of human activities on the environment aimed at controling environmental pressures [17], namely the IPAT model: $\mathrm{I}=\mathrm{P} \times \mathrm{A} \times \mathrm{T}$. IPAT specifies three key driving forces for environmental change: population(P), affluence (A), and technology(T).

As a follow-up study, Waggoner and Ausubel [18] further disaggregated a fourth variable $-\mathrm{C}$ (the intensity of energy use) into per unit of GDP (A) and impact per unit of consumption $(\mathrm{T})$ - so that a new model called ImPACT was set. Although ImPACT advanced the IPAT model in allowing room for diagnostic analysis, both were equations with fixed factors assuming proportionality between the key determinant factors, which limit further application of the models. Moreover, the effects of the driving forces are usually nonlinear and non-proportional, causing adverse impact to the application of IPAT and ImPACT. To overcome these limitations, a new model named STIRPAT was proposed by Dietz and Rosa, which gives a chance to introduce more variables during analysis and is much more flexible to test the impacts of each factor on environmental pressures.

According to the basic STIRPAT model, many new factors were added considering their influence on carbon emissions. Song et al. [19] concluded that population, GDP per capita, industrial structure, energy consumption intensity, and energy consumption structure are the important impact factors of carbon emissions through a STIRPAT model. New research showed that urbanization increases energy consumption and $\mathrm{CO}_{2}$ emissions in China [20]. York et al. found urbanization and industrialization were associated with high impacts on $\mathrm{CO}_{2}$ emissions by a refined STIRPAT model [21]. In addition, STIRPAT combined with PLS regress analysis was adapted to prove that urbanization level had the greatest interpretative ability for $\mathrm{CO}_{2}$ emissions [22]. Lin et al. [23] tried to expand the basic model with urbanization factor through China's data analysis from 1978 to 2006, and it was demonstrated that urbanization level was of secondary importance to the impact on $\mathrm{CO}_{2}$ emissions. In this paper, an extended STIRPAT model can be used to predict the 
peak value of $\mathrm{CO}_{2}$ emissions in future decades, and Ridge regression would be used to deal with multi-collinearity. Ridge regression has been applied in several different research aspects, such as environmental science [24] and software cost dataset [25], to overcome this problem. Ridge regression was also used to fit the extended STIRPAT model to examine the impact factors of $\mathrm{CO}_{2}$ emissions in Guangdong Province [26].

\section{Methodology}

\section{Measurement of $\mathrm{CO}_{2}$ Emissions}

Carbon emissions (unit: million tons) is worked out on the basis of various energy consumption found from the Beijing, Tianjin, Hebei, and Chinese statistical yearbooks. The specific formula released by 2006 IPCC guidelines is:

$$
\mathrm{CE}=\sum_{v} E_{v} \times N C V \times C E C_{v} \times C O F \times \frac{44}{12}
$$

...where $\mathrm{CE}$ is the total amount of carbon emissions, $\mathrm{E}_{\mathrm{v}}$ refrs to the vth kind of primary energy consumption, $\mathrm{NCV}$ denotes net calorific value, $\mathrm{CEC}_{\mathrm{y}}$ is carbon emissions coefficient of the vth kind of primary energy consumption, $\mathrm{COF}$ indicates carbon oxidation factor (and the recommended value is normally $100 \%$ according to 2006 IPCC guidelines), and s represents departments. It is obvious that the carbon emissions under various sectors or diverse technological levels are co-determined by NCV, $\mathrm{CEC}$, and $\mathrm{COF}$.

\section{STIRPAT Model}

The general format of the STIRPAT model can be specified as follows:

$$
I_{i}=\alpha P_{i}^{b} A_{i}^{c} T_{i}^{d} e_{i}
$$

Being a non-linear model, the natural logarithm can be taken on STIRPAT to analyze the non-proportional impacts on the environment. The new formula is as follows:

$$
\ln I_{t}=\ln \alpha+b \ln \left(P_{t}\right)+c \ln \left(A_{t}\right)+d \ln \left(T_{t}\right)+\ln e_{t}
$$

...where I denotes environmental impact; population (P) elasticity, affluence (A) elasticity, and technology (T) elasticity are respectively taken as the decisive factors; a is a constant; and b, c, and d are the coefficients for P, A, and $\mathrm{T}$. The subscript $\mathrm{t}$ indicates the year and e across the error term.

The STIRPAT method has been applied in many papers to investigate the impacts of driving forces on $\mathrm{CO}_{2}$ emissions. Except for the basic exponents of $\mathrm{P}, \mathrm{A}$, and $\mathrm{T}$, industrial structure, energy consumption intensity and urbanization were considered extra driven factors of $\mathrm{CO}_{2}$ emissions using the STIRPAT model.

In this paper the extended STIRPAT model is built with six factors to estimate carbon emissions. Considering the results of several studies about Kuznets curve theory [27], there is no longer a linear relationship between economic development and carbon emissions, and the square term of economic development has been included in studies. Aiming at avoiding zero or negative indicators, many studies have worked on a (natural) logarithmic transformation of environmental degradation and square term of economic development [28]. Besides, the carbon footprint of energy in Shanghai was studied to explore the relationship between carbon footprint and economic development with an expanded model including both the affluence (A) and the square term [29]. According to all of the information, the final formula in this paper is expressed as follows:

$$
\begin{aligned}
\ln C E= & \ln a+\beta_{1} \ln \mathrm{A}^{2}+\beta_{2} \ln \mathrm{P}+\beta_{3} \ln \mathrm{T}+ \\
& +\beta_{4} \ln \mathrm{UR}+\beta_{5} \ln \mathrm{ES}+\beta_{6} \ln \mathrm{I}
\end{aligned}
$$

...where $\mathrm{CE}$ illustrates the scale of $\mathrm{CO}_{2}$ emissions; $\mathrm{A}^{2}$ refers to the squared term of GDP per capita; $\mathrm{P}$ and $\mathrm{T}$, respectively, denote population (year-end) and technological levels; UR is the urbanization level; ES refers to energy structure; and I means industrial level. The variables are described in Table 1.

Table 1. Explanation of variables used in this paper.

\begin{tabular}{|c|c|c|c|}
\hline Symbol & Variable & Definition & Unit of measurement \\
\hline $\mathrm{CE}$ & $\mathrm{CO}_{2}$ emissions & Total carbon emissions & 10,000 tons \\
\hline $\mathrm{A}$ & Affluence level & GDP per capita & Yuan in constant 2000 price \\
\hline $\mathrm{P}$ & Population & population size & 10,000 units \\
\hline $\mathrm{T}$ & Technological level & $\mathrm{CO}_{2}$ emissions per unit of GDP & ton $/ 10^{4}$ Yuan \\
\hline $\mathrm{UR}$ & Urbanization level & The ratio of urban population in total over total population & $\%$ \\
\hline $\mathrm{ES}$ & Energy structure & The proportion of non-fossil energy to total energy consumption & $\%$ \\
\hline $\mathrm{I}$ & Industrial level & The secondary industry share of GDP & $\%$ \\
\hline
\end{tabular}


In this paper the STIRPAT model was applied not only to show the impacts of the driving forces on $\mathrm{CO}_{2}$ emissions in the Beijing-Tianjin-Hebei region over the last 13 years in the survey stage, but also to forecast the peak value of $\mathrm{CO}_{2}$ emission under different scenarios.

\section{Ridge Regression}

The classical multiple linear regression model is given $[30,31]$ by:

$$
\mathrm{Y}=\mathrm{X} \beta+\varepsilon
$$

...where $\mathrm{Y}$ is a $(\mathrm{n} \times 1)$ matrix of dependent variables and $X$ is $a(n \times p)$ array of independent variables. $\beta$ is a $(p \times 1)$ vector of coefficients and $\varepsilon$ notes the normally distributed random errors.

As one of the most universal methods, the ordinary least square (OLS) regression is frequently used for parameter estimate [32]. The estimation of $\beta$ is given as Eq. (6) :

$$
\widehat{\beta}=\left(X^{\prime} X\right)^{-1} X^{\prime} Y
$$

Two vital properties should be satisfied for OLS:

$$
\mathrm{E}(\hat{\beta})=\beta, \operatorname{Var}(\hat{\beta})=\sigma^{2}\left(X^{\prime} X\right)^{-1}=\sigma^{2} \sum_{i=1}^{p} \frac{1}{\lambda_{i}}
$$

When multi-collinearity exists between the variables, this variance will be small (which contrarily turns to be a large value), and the OLS estimates of coefficient become unstable, having large variance [33].

As a kind of improved algorithm, ridge regression added a non-negative factor $\mathrm{k}$ to the main diagonal of standard system matrix. Thus, the OLS estimation problem was solved by biased ridge regression parameter estimation as below:

$$
\hat{\beta}(k)=\left(X^{\prime} X+k I\right)^{-1} X^{\prime} y, k>0
$$

It has been demonstrated by Hoerl and Kennard that a series of $\mathrm{k}$ existed to ensure a smaller mean squared error (MSE) of ridge regression estimates than MSE of the ordinary least square estimates. Specifically, the estimator of ridge regression turned back to OLS estimator $(\beta)$ under the situation $\mathrm{k}=0$.

The $\operatorname{MSE}[\hat{\beta}(k)]_{r r}$ and $\operatorname{MSE}[\hat{\beta}(k)]_{o l s}$ are obtained, respectively, as follows:

$$
\begin{gathered}
\operatorname{MSE}[\hat{\beta}(k)]_{r r}= \\
\left.k^{2} \beta^{\prime} X^{\prime} X+k I\right)^{-2} \beta+\sigma^{2} \sum_{i=1}^{p} \frac{\lambda_{i}}{\left(\lambda_{i}+k\right)^{2}} \\
\operatorname{MSE}[\hat{\beta}(k)]_{o l s}=\sigma^{2} \sum_{i=1}^{p} \frac{1}{\lambda_{i}}
\end{gathered}
$$

\section{Empirical Results and Discussion}

Data Source

Panel data used in the calculation process were obtained respectively from the Beijing, Tianjin, Heber, and Chinese statistical yearbooks, including per capita gross regional product (yuan/person) and population (year-end, 10,000 persons). Although some variables are difficult to obtain directly in references, they can be figured out through fixed formula.

Specifically, urbanization level is defined as a percentage of urban population; technological level is reflected by the ratio of carbon emissions and the gross regional product, namely carbon emission intensity, which is a kind of regional energy efficiency indicator. Industrial level and energy consumption structure are explained, respectively, as the secondary industry share of GDP and percentage of coal consumption to total energy consumption.

\section{Multicollinearity Test}

For all of the independent variables, the multicollinearity test should be taken to testify the drawback of OLS. Actually, social development, population, urbanization level, and GDP per capita would increase accordingly with economic development and social progress. Relying on the results shown in Tables 2 and 3 , it is clear that the correlations of more than half of the variables, including affluence, population, urbanization, and technology level, are high and the VIF values, which is one of the most common criteria [34], of population, urbanization level, technological level, and GDP per capita are much higher than 10 . That is to say, serious multicollinearity exists between these variables, which would be conducive to an unstable status to the regression coefficients. For the reason of possible interaction between variables, the variables' marginal influence cannot be reflected by the regression coefficients obtained through OLS.

\section{Ridge Regression Estimation}

The ridge regression method is adopted here in forming the multiple linear regression model to avoid

Table 2. Results of correlation test.

\begin{tabular}{|c|c|c|c|c|c|c|}
\hline & $\ln \mathrm{A}^{2}$ & $\ln \mathrm{P}$ & $\ln \mathrm{UR}$ & $\ln \mathrm{T}$ & $\operatorname{lnES}$ & $\ln \mathrm{I}$ \\
\hline $\ln \mathrm{A}^{2}$ & 1 & & & & & \\
\hline $\ln \mathrm{P}$ & $0.973^{*}$ & 1 & & & & \\
\hline $\ln \mathrm{R}$ & $0.991^{*}$ & 0.942 & 1 & & & \\
\hline $\ln \mathrm{T}$ & $-0.996^{*}$ & -0.976 & $-0.988^{*}$ & 1 & & \\
\hline $\ln \mathrm{ES}$ & $-0.245^{*}$ & $-0.442 * *$ & $-0.165^{* *}$ & $0.272 * *$ & 1 & \\
\hline $\ln \mathrm{I}$ & 0.026 & -0.096 & 0.024 & $0.027 * *$ & 0.393 & 1 \\
\hline
\end{tabular}


Table 3. Results of OLS regression.

\begin{tabular}{|c|c|c|c|}
\hline OLS result & $\begin{array}{c}\text { Unstandardized } \\
\text { coefficient }\end{array}$ & $\begin{array}{c}t \text {-Statistic } \\
\text { Sig. }\end{array}$ & VIF \\
\hline Constant & -7.359 & 0.116 & \\
\hline $\ln \mathrm{A}^{2}$ & .412 & 0.000 & 934.578 \\
\hline $\ln \mathrm{P}$ & .743 & 0.089 & 257.123 \\
\hline $\ln \mathrm{UR}$ & 0.469 & 0.020 & 206.301 \\
\hline $\ln \mathrm{T}$ & 0.946 & 0.000 & 216.777 \\
\hline $\operatorname{lnES}$ & 0.001 & 0.994 & 6.977 \\
\hline $\ln \mathrm{I}$ & 0.223 & 0.101 & 3.145 \\
\hline Adjusted $R^{2}$ & 1.000 & & \\
\hline$F$-statistic Sig. & 0.000 & & \\
\hline
\end{tabular}

the limitations of OLS. The validity of the proposed regression model can be checked by reliable indicators such as adjusted $\mathrm{R}^{2}$, $\mathrm{t}$-test, and F-test. Table 3 demonstrates that the fitting degree (adj. $\mathrm{R}^{2}=1.000$ ) is excellent and the regression equation is significant (F-statistic Sig.<0.05). However, half independent variables are not significant (t-Statistic Sig.>0.05).

The ridge regression is used to estimate the coefficients in the STIRPAT model. According to the ridge regression Eq. (8), ridge trace and the $\mathrm{R}^{2}$ versus $\mathrm{k}$ are respectively demonstrated by Figs 1 and 2. To clearly show the change of regression coefficients and find the least $\mathrm{k}$ value, only 51 points have been drawn in Fig. 1 becaue the coefficients all maintain the stable trend with little change when $\mathrm{k}$ increase from 0.5 to 1 . The standardized regression coefficients of each independent variable change quickly at first with the increse of $\mathrm{k}$ value, and their coefficients sharply turn to be fixed with few changes after $\mathrm{k}=0.01$. Fig. 2 shows that the $\mathrm{R}^{2}$ of ridge regression changes with a high change rate before $\mathrm{k}=0.01$, and the rate becomes much lower from the $\mathrm{k}$ value of 0.01 . That is to say, the smallest value of $\mathrm{k}(\mathrm{k}=0.01)$ can be performed with a high adjusted $\mathrm{R}^{2}$ of 0.992 . Thus, it is reasonable to choose $\mathrm{k}=0.01$ in this paper considering good interpretability.

The $\mathrm{F}$ test can be passed with the result of $\mathrm{F}$ Sig. $($ Sig. $=0.0000005<0.05)$, which means there is a linear relationship between independent variables and dependent variable. Besides, the regression coefficient's t Sig. of each independent variable and constant term also can meet the requirement $(<0.05)$, which indicates that all of the independent variables should be in the regression equation. The details are presented in Table 4.

Using ridge regression, the model is:

$$
\begin{gathered}
\operatorname{lnCE}=-14.03+0.1045 \ln \mathrm{A} 2+ \\
1.59 \ln \mathrm{P}+0.0274 \ln \mathrm{T}+0.6857 \ln \mathrm{R} \\
+0.4235 \ln \mathrm{ES}+0.9679 \ln \mathrm{I}
\end{gathered}
$$

According to the predicted value (from 2000 to 2012) calculated by Eq. (11) and real $\mathrm{CO}_{2}$ emissions, the maximum absolute value of relative error is measured at $0.6 \%$. That is to say, this is a proper model with a high quality of fit.

\section{Analysis of Results of Ridge Regression}

The empirical results demonstrate that the values of independent variables' coefficients are as expected. The relationships between $\mathrm{CO}_{2}$ emissions and each independent variable are positive. According to the ridge regression result, not only the augmented population, GDP per capita, and urbanization levels, but also the deteriorative promotion of energy structure and the secondary industry level are conducive to $\mathrm{CO}_{2}$ emissions' increase. Besides,

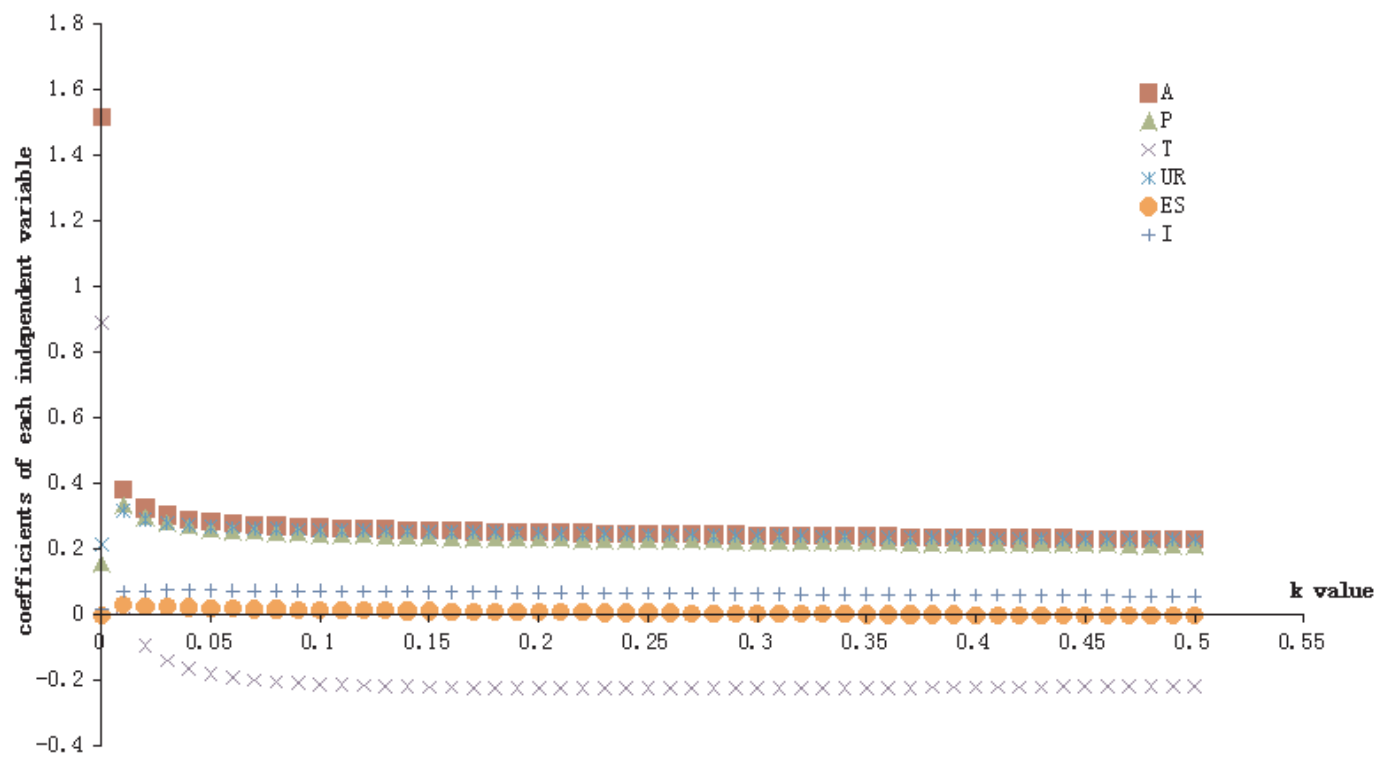

Fig. 1. Curves of ridge trace. 


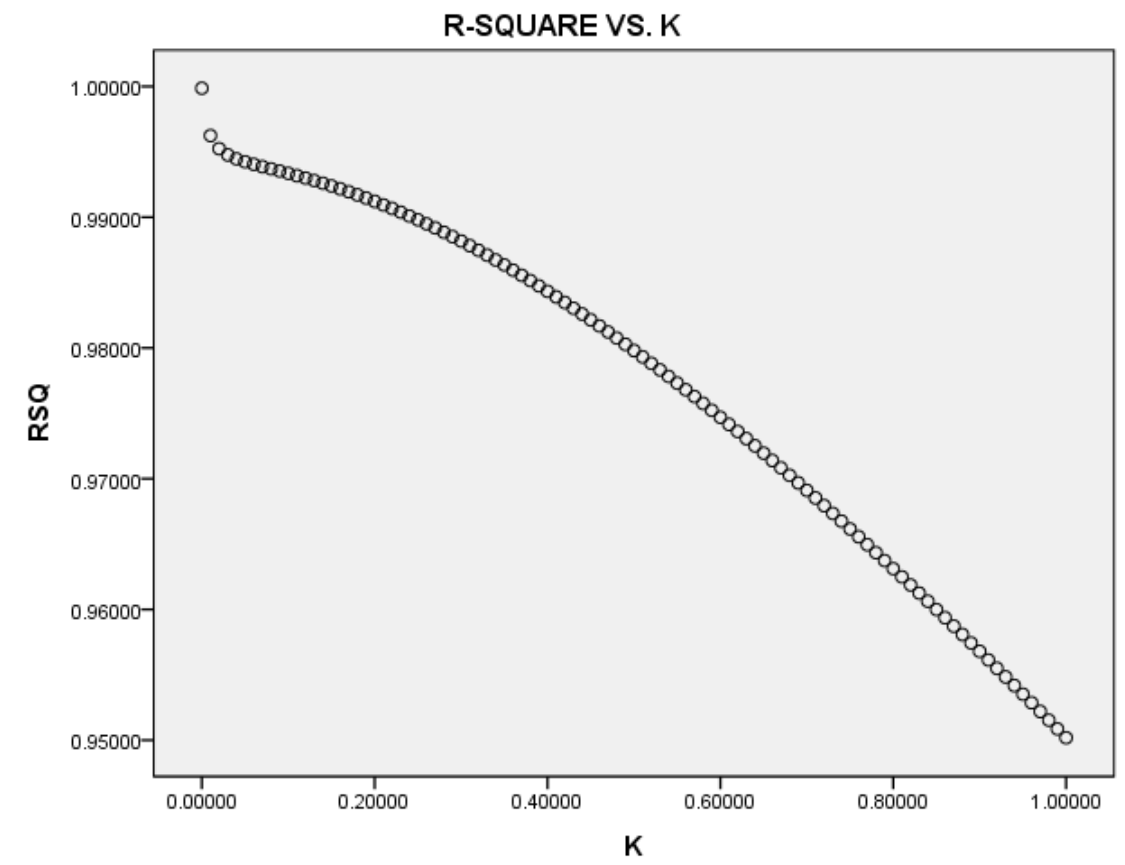

Fig. 2. Changes of $\mathrm{k}$ under different RSQ.

Table 4. Results of tests for each independent variable and constant.

\begin{tabular}{|c|c|c|c|c|c|c|c|}
\hline & constant & $\ln \mathrm{A}^{2}$ & $\ln \mathrm{P}$ & $\ln \mathrm{T}$ & $\ln \mathrm{UR}$ & $\ln \mathrm{S}$ & $\ln \mathrm{I}$ \\
\hline Student's test & $-2.57^{* *}$ & $6.65^{* * *}$ & $3.45^{* *}$ & $1.87^{*}$ & $3.28^{* *}$ & $1.42^{*}$ & $2.64^{* *}$ \\
\hline
\end{tabular}

Note: *** significant at $1 \%, * *$ significant at $5 \%$

the advance of technology level - namely the decrease in $\mathrm{CO}_{2}$ emissions per unit of GDP - results in an adverse influence on carbon emissions. The importance of each impact factor can be expressed by the absolute values of variables' coefficients. Population holds the largest effect on emissions, followed by secondary industry level, urbanization level, energy consumption structure, the squared term of GDP per capita, and technology level in a downward trend. Next we discuss the influences of these independent variables on $\mathrm{CO}_{2}$ emissions.

\section{Population}

The growth of population generates the largest increase on the scale of the Beijing-Tianjin-Hebei region's carbon emissions with an elastic coefficient at 1.59 , which means a $1.59 \%$ growth in $\mathrm{CO}_{2}$ emissions from every $1 \%$ growth in total population. As the political and economic center, the region's average population growth rate of more than $1.4 \%$ is 2.46 times as high as China's from 2000 to 2012 . The high growth rate mainly contributes to the constant increase of immigrants.

\section{The Secondary Industry Level}

$\mathrm{CO}_{2}$ emissions are less responsive to changes in this factor, which is defined by the percentage of the secondary industry (elastic coefficient $=0.9679)$ including mining, manufacturing, electricity, water production, supply industry, and construction sectors. The elastic coefficient illustrates a $0.9679 \%$ growth in $\mathrm{CO}_{2}$ emissions owing to a $1 \%$ increase in the secondary industry level. In the phase of urbanization and industrialization, although it is normal for secondary industry dominating the largest percentage among the whole industry in China, the percentage of the secondary industry in Beijing, Tianjin, and Hebei fluctuates year-to-year in intervals of from $41 \%$ to $45.16 \%$, which were always lower than the percentage of the third industry over the last 13 years. Due to the fact that the secondary industry consumes a majority of energy during its production, its progressive decrease seems to be a key promotion to the decrease of $\mathrm{CO}_{2}$ emissions.

\section{Urbanization Level}

Urbanization level plays an important role in the influence on $\mathrm{CO}_{2}$ emissions. The elastic coefficient is 0.6857 based on the result, indicating a $0.6857 \%$ increase in the $\mathrm{CO}_{2}$ emissions owing to a $1 \%$ increase in percentage of urban population in total. The growth of demand for energy is associated with urbanization level, which in turn leads to more $\mathrm{CO}_{2}$ emissions. This circumstance can be explained by the modern lifestyle in the urban area, where people tend to consume more energy to ensure convenient, 
comfortable, and rich living conditions. Through analysis of data, both the number and average growth rate of the proportion of urban population in the Beijing-TianjinHebei region are higher than China's average level from 2000 to 2012.

\section{Structure of Energy Consumption}

In the long run, all of China, including the BeijingTianjin-Hebei region, relies on the traditional coalintensive energy structure. Thus coal consumption to total energy consumption (elastic coefficient $=0.4235$ ) is the best indicator to describe energy structure. The elastic coefficient shows that every $1 \%$ increase in percentage of coal consumption industrialization level leads to a $0.4235 \%$ increase in $\mathrm{CO}_{2}$ emissions. Coal also occupies a vital position in the Beijing-Tianjin-Hebei region's energy consumption in the past 12 years. From 2000 to 2012, coal took up a large share of $78.45 \%$ in total energy consumption, which was even higher than the average level of all of China [35].

\section{The Square Term of GDP per Capita}

The impact of $\mathrm{A}^{2}$ on $\mathrm{CO}_{2}$ is comparatively lower with an elastic coefficient at 0.0865 , which illustrates that $\mathrm{CO}_{2}$ emissions increased by merely $0.1045 \%$ when the square term of GDP per capita increased 1\%. The Beijing-TianjinHebei region would bear more gradually increasing pressure from $\mathrm{CO}_{2}$ emissions followed by growth of population, energy consumption, and living cost, which is to some extent an unavoidable process for rapid economic development at this period.

\section{Technology Level}

Technology level is presented by the $\mathrm{CO}_{2}$ intensity $\left(\mathrm{CO}_{2}\right.$ emissions per unit of GDP), which has a minimal regression coefficient of 0.0274 , meaning that a one percent increase in technology level leads to $0.0274 \%$ change in $\mathrm{CO}_{2}$ emissions. Coming with technological innovation, a continual decrease in $\mathrm{CO}_{2}$ intensity is helpful for reducing carbon emissions. The data of the BeijingTianjin-Hebei region shows a gradual decline in the phase from 2000 to 2012, and this trend tends to proceed with a reducing change rate.

\section{Scenario Designs for the Possible Peak Value of $\mathrm{CO}_{2}$ Emissions}

\section{Design of Driven factors}

Based on the model established in this paper, eight kinds of scenarios aimed at the Beijing-Tianjin-Hebei region's socio-economic development in the coming 38 years, are established to make a forecast of $\mathrm{CO}_{2}$ emissions. In this paper, the future trend of each factor is divided, considering different social, economic, and technological policies, and lifestyle and relative targets, into three situations with different speed (low, medium, and high). The driven factors are reliably designed on the following details, and Table 5 provides the variations of each factor.

\section{Population}

From 2000 to 2012 the average population growth rate in the Beijing-Tianjin-Hebei region was much higher than in the whole China. Zhang et al. [36] analyzed the trend of the region's population through the cohort-component method. They concluded that the average growth rate from 2013 to 2020 showed no clear sign of decline and the growth rates of low, medium, and high models are, respectively, $0.8 \%, 1.1 \%$, and $1.2 \%$. Additionally, the region is an administration center rather than an ordinary economic development zone in China. Although there are many solutions and relative policies to inhibit the growth of population, the large number of immigrants still puts severe pressures on this region to reach maximum population around the year 2030. Thus, the population peaks, respectively, in 2030, 2035, and 2040 in the low, medium, and high models.

\section{The Urbanization Level}

The ratio of urban population in the region, maintaining a distinct increasing tendency, was higher than China's average level from 2000 to 2012. Additionally, the ratio of urban population in the Beijing-Tianjin-Hebei economic band was only $55.01 \%$, which is lower than the ratios in the other two important economic support zones of China - the Yangtze River Delta and the pan-Pearl River Delta - by, respectively, 8.69 percentage points and 27.69 percentage points. All of this shows the potential for the Beijing-Tianjin-Hebei economic band to reach a higher extent of urbanization. Thus, the percentage of urban population in this district is designed to be $83 \%$ through a period of 38 years under a high tempo. The urbanization level gradually increased to $79 \%$ and $70 \%$, respectively, under medium and low, which were designed after consulting LBNL, ERI, and UNDP.

\section{GDP per Capita}

The assumption about GDP per capita is based on a regulation that growth rate of GDP per capita would gradually be reduced with economic development [37]. This article firstly set the variation tendency of GDP. Then, the corresponding GDP per capita can be calculated with the given data of population. In this research, both low and medium modes have the same growth curve of GDP, which is set mainly according to the output of ERI. Actually, the variation of GDP per capita (from 2013 to 2050 ) in these two conditions can be different because they would be divided by a different number of population. The growth rate of GDP with high speed is set a little higher than the others considering the Beijing-Tianjin-Hebei economic band's advantage of economic development. The calculated GDP per capita to the year 2050 under a 
Table 5. The different modes of each driven factors.

\begin{tabular}{|c|c|c|}
\hline Variables & Modes & Targets \\
\hline \multirow{3}{*}{ Population } & Low speed & Population reach a peak by 2030 \\
\hline & Medium speed & Population reach a peak by 2035 \\
\hline & High speed & Population reach a peak by 2040 \\
\hline \multirow{3}{*}{ Urbanization level } & Low speed & The level is $70 \%$ in 2050 \\
\hline & Medium speed & The level is $79 \%$ in 2050 \\
\hline & High speed & The level is $83 \%$ in 2050 \\
\hline \multirow{3}{*}{ GDP per Capita (yuan) } & Low speed & GDP per capita is more than 50000 in 2050 \\
\hline & Medium speed & GDP per capita is more than 53000 in 2050 \\
\hline & High speed & GDP per capita is more than 68000 in 2050 \\
\hline \multirow{3}{*}{ Secondary industry level } & Low speed & The level is $38 \%$ in 2050 \\
\hline & Medium speed & The level is $37 \%$ in 2050 \\
\hline & High speed & The level is $36 \%$ in 2050 \\
\hline \multirow{3}{*}{ Energy construction } & Low speed & The level is $56 \%$ in 2050 \\
\hline & Medium speed & The level is $40 \%$ in 2050 \\
\hline & High speed & The level is $30 \%$ in 2050 \\
\hline \multirow{3}{*}{ Technological level } & Low speed & The level in 2050 is $55 \%$ lower than the 2012 level \\
\hline & Medium speed & The level in 2050 is $73 \%$ lower than the 2012 level \\
\hline & High speed & The level in 2050 is $84 \%$ lower than the 2012 level \\
\hline
\end{tabular}

high model is more than $\$ 60,000 \mathrm{US}$. This can be regarded as a reasonable assumption for the reason that the value is similar to the GDP per capita of the developed countries in 2013, such as Denmark $(\$ 60,564)$ and Australia $(\$ 61,219)$ [38].

\section{The Secondary Industry Level}

The level is the ratio of the secondary industry. ERI and UNDP have similar conclusions about industry structure $[14,15,2]$, where the secondary industry share of GDP in 2050 is in the interval from $36 \%$ to $38 \%$. Thus, to 2050 the secondary industry model levels of low, medium, and high are respectively designed as $36 \%, 37 \%$, and $38 \%$ under different change rates.

\section{Energy Construction}

The demand for primary energy will increase until 2050 in the Beijing-Tianjin-Hebei region at a slower rate. And the coal in the primary energy would count as a large proportion for a long time. Although degrees are various, kinds of ratio of coal in different research are in a downward trend. The basic scenario and low carbon emissions scenario of IEA [1] present the ratio of coal as $56 \%$ and $30 \%-$ similar to the forecast in ERI $[14,15]$. So it is reasonable to suppose the proportion of coal under low, medium, and high mode as, respectively, 56\%, 40\%, and $30 \%$.

\section{Technological Level}

In China, the difficulty of this level would increase along with the going on of governance. Namely, the decline rate in $\mathrm{CO}_{2}$ emissions per unit of GDP would gradually decrease. The data from 2000 to 2012 illustrate that the $\mathrm{CO}_{2}$ intension in the Beijing-Tianjin-Hebei region is in a decrease trend due to the continually technological reformation. According to the output of UNDP, to the year of 2050 the reduced carbon emissions intensity is $73 \%$ under the basic scenario, and the carbon emissions intensions under the emissions control (EC) scenario and emissions abatement (EA) scenario are, respectively, 58\% and $34 \%$ of the value in the basic scenario. Hence, the technological levels in 2050 under low, medium, and high models will, respectively, take the proportion of the value in 2010 by $68.7 \%, 40 \%$, and $23.5 \%$.

\section{Design and Selection of Scenarios}

Based on these designs of driven forces, eight scenarios for the period covered from 2013 to 2050 are devised to forecast the situation of carbon emissions. Succinctly put, all of the factors are divided into two groups. Group one contains population, urbanization level, and GDP per capita, which mainly retains an upward trend in future decades and has a positive impact on $\mathrm{CO}_{2}$ emissions; group two includes secondary industry level and energy construction and technological level, which are predicted 
Table 6. Parameter designs of eight scenarios.

\begin{tabular}{|c|c|c|c|c|c|c|}
\hline Scenario & P & A & UR & T & I & ES \\
\hline S1 & M & M & M & L & L & L \\
\hline S2 & M & M & M & M & M & M \\
\hline S3 & H & H & H & M & M & M \\
\hline S4 & H & H & H & H & H & H \\
\hline S5 & M & M & M & H & H & H \\
\hline S6 & L & L & L & L & L & L \\
\hline S7 & L & L & L & M & M & M \\
\hline S8 & H & H & H & L & L & L \\
\hline
\end{tabular}

to be on a gradually downward trend and help to stop the increase of $\mathrm{CO}_{2}$ emissions. Table 6 provides the clear instruction of different scenarios.

Scenario 1: This scenario is an embodiment of the basic situation. Economic growth and development will still be primal, but several extra policies might be announced to spread low-carbon measures, helping slow down economic development to some extent. Urbanization level will increase at a relatively quick rate with regional development, which will be $79 \%$ in 2050 . Population will be high in the first decade and decrease quickly to reach a peak in 2035. As for energy construction and technological level, there is only a maintenance of current mainstream technologies such as supercritical and ultra-supercritical technology, and the dominant source of primary energy will still be coal, but with a smaller share.

Scenario 2: Compared with S1, S2 pays more attention to energy conservation with all of the factors in group two changing at medium speed. The ratio of coal will decrease to $40 \%$ due to more use of oil and natural gas. There will also be a quickly enlarged demand for nuclear power and nonhydro renewable energy technologies, but their shares are still little. The existing technologies will be broadly used to increase generating efficiency, but new technologies, such as CCS, would not be considered. With the transfer to the advanced stage of industrialization, the secondary industry share of GDP will decline with a clear aim.

Scenario 3: This scenario will mainly focus on economic development and urbanization. The urbanization level in this district will eventually exceed the level in the Pearl River Delta and the GDP per capita will be more than $\$ 60,000$ by 2050 , which is similar to Denmark's current situation.

Scenario 4: Similar to Scenario 3, the driving factors belonging to group two will be given more concern, but the increasing speed of GDP per capita, population, and urbanization level will not decrease. In S4, the GDP per capita, population, and urbanization level will keep high mode, reaching a high standard in 2050, and the $\mathrm{CO}_{2}$ emissions will not be out of control owing to a widespread exertion of expensive low-carbon technologies such as electric motors, nuclear power, and carbon capture and storage (CCS). The government will incentivize the expansion of new renewable technologies such as wind power and solar power to change the dominant status of coal.

Scenario 5: As a comparison with S4, this scenario focuses on the impact on $\mathrm{CO}_{2}$ emissions of medium economic, population, and urbanization development. Under the same development trend of industry and energy technology, the medium speed of economics, population, and urbanization might eventually decrease carbon emissions in the Beijing-Tianjin-Hebei region for the reason that socio-economic, population development, and urbanization factors can be controlled to some extent in China.

Scenario 6: In S6 all of the independent variables will vary at low speed, which is actually an economic recession scenario. The population will peak in 2030 and the rate of economic development will be extremely low in 2050 . Besides, up until 2050 the urbanization level will be $70 \%$ - even lower than Pearl River Delta Region's current level. This kind of design means faint development in this region and low emissions at the same time. So, the $\mathrm{CO}_{2}$ emissions will still reach their maximum value before 2050, although the solutions and governance about energy consumption, industry structure, and carbon abatement technology are slender.

Scenario 7 focuses more on environmental protection compared with S6.

Scenario 8: S8 pays much more attention to the rise of the economy, population, and urbanization (in high model), but less to industry level, energy construction, and technological level (in low model). The situation of $\mathrm{CO}_{2}$ emissions might be out of control with so much partiality to socio-economic development.

\section{Analysis Based on Predicted $\mathrm{CO}_{2}$ Emissions of Different Scenarios}

In this paper the changing track of each independent variable can be obtained through the situations described previously. Subsequently, the $\mathrm{CO}_{2}$ emissions in different scenarios can be predicted through the STIRPAT model. Different predicted tracks of $\mathrm{CO}_{2}$ emissions in the period from 2013 to 2050 are shown in Fig. 3.

Under the basic scenario ( $\mathrm{S} 1$ ), the $\mathrm{CO}_{2}$ emissions in the Beijing-Tianjin-Hebei region will grow quickly to $1,187.5$ million tons in 2030 and increase with a moderate trend to 1,296.2 million tons in 2050 .

In S2, the emissions will turn to decrease after 2039. The total volumes of $\mathrm{CO}_{2}$ emissions in 2050 and in 2028 are similar, but the GDP per capita and ratio of urbanization will see dramatic growth. Under S2, more solutions will be implemented as a promotion to energy efficiency, the drop of carbon intensity and adjustment of energy structure. Besides, alternation of the industry structure is essential for the Beijing-Tianjin-Hebei region to decline its ratio of secondary industry. As a result, by 2050 the $\mathrm{CO}_{2}$ emissions in $\mathrm{S} 2$ will be lower by 215.5 million tons than in $\mathrm{S} 1$.

In S3 the Chinese Government will contribute to establishing a flourishing society under a moderate input 


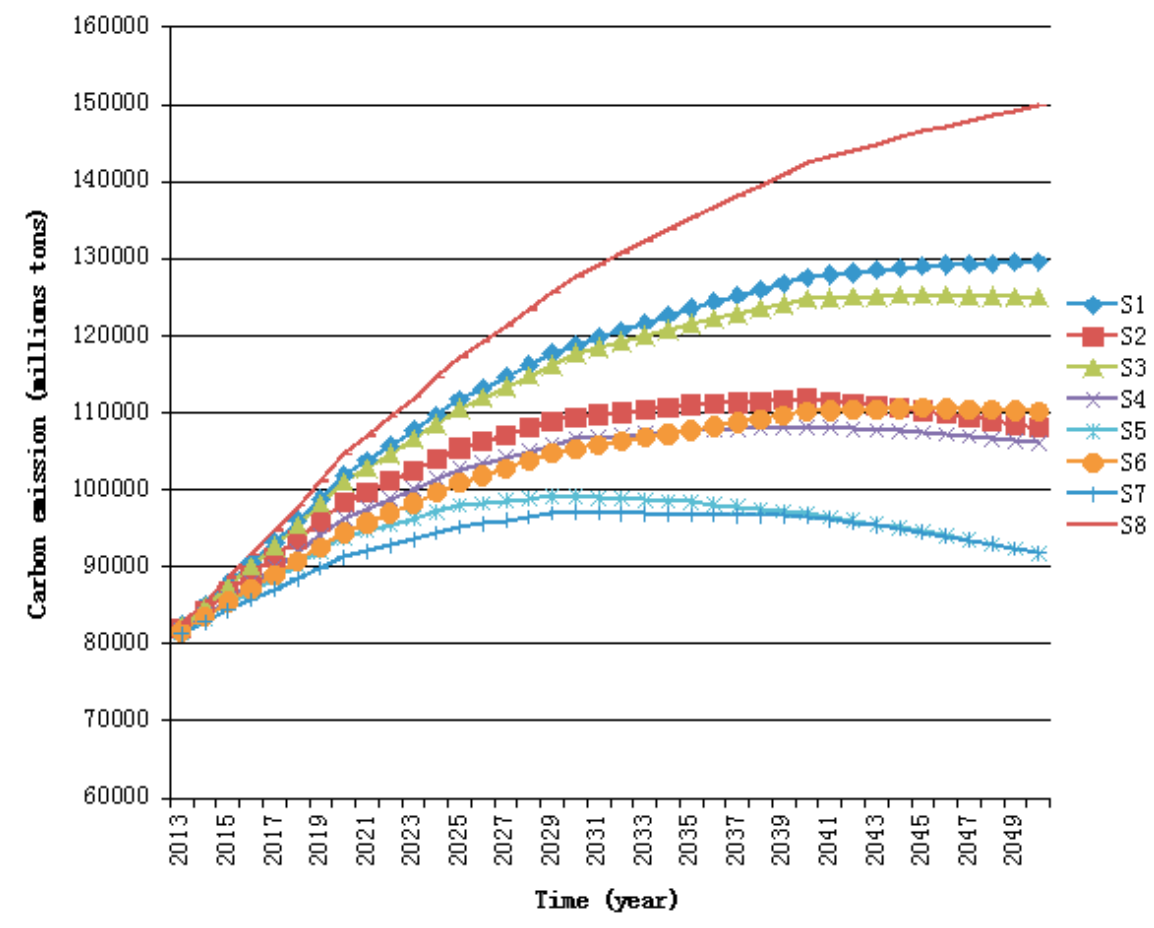

Fig. 3. Curves of $\mathrm{CO}_{2}$ emissions under eight scenarios.

in controlling emissions. To satisfy the aim of economic development in the studied region, local government will try to introduce more talent and insist on urban construction. The expansion of urbanization cannot be avoided during this period [39]. The similar improvement level of technology, energy consumption, and industry adjustment with S2, increased GDP, urbanization, and population will cause growth in carbon emissions. Thus, considering the restrictions imposed by technology, industry construction, and clean energy supply capabilities, $\mathrm{CO}_{2}$ emissions in $\mathrm{S} 3$ will rise to $1,252.4$ million tons in 2045 and be reduced to $1,249.2$ million tons in 2050 .

In $\mathrm{S} 4$, governments in the studied region will treat economic development as a fundament to invigorate its quality of life and will make tight advancement to technology, industry, and new energy. S4 is quite appropriate in terms of emissions, but governments will bear considerable pressures to reach emissions targets. In this scenario, except for the broad use of supercritical and ultra-supercritical technology, more investments will be made in integrated gasification combined-cycle plants (IGCC) as well as carbon capture and storage (CCS). The ratio of coal consumption will gradually decrease in order to generate more electricity from nuclear, hydro, and wind power. Additionally, the ratio of the secondary industry will be reduced during the process of GDP growth. Laborintensive industries as well as capital-intensive industries would be improved first in the decreasing process. Under this scenario, China's $\mathrm{CO}_{2}$ emissions would decline from $1,060.7$ million tons in 2040 .

Under S5, the $\mathrm{CO}_{2}$ emissions turn to reduce in 2029 presents the best consequence of emissions among all these scenarios. The same melioration about technology, energy consumption, and the secondary industry with S3 makes it technologically possible for the BeijingTianjin-Hebei region's control of $\mathrm{CO}_{2}$ emissions. Besides, population, GDP per capita, and urbanization levels are all in the medium increase mode, which means fewer sources of emissions. The $\mathrm{CO}_{2}$ emissions in $\mathrm{S} 5$ will arrive at peak in 2029 .

Economic development has been ranked first for a long time in the Beijing-Tianjin-Hebei region. Thus, solutions for emission problems should come with no negative influence on socio-economic development. The status of $\mathrm{CO}_{2}$ emissions in S6 and S7 show well. However, these two scenarios cannot be accepted because of their low development speed.

The curve of S8 is a contrast with S3 and S4. The emission figure under S8 will continue to grow at 1,498.3 million tons, which is, respectively, 19.9 percent and 41.3 percent more than emissions under S3 and S4. The enormous disparity of $\mathrm{CO}_{2}$ emissions demonstrate that investment in technology, energy consumption, and industry adjustment is essential and rewarding.

\section{Development Strategies for Low $\mathrm{CO}_{2}$ Emissions}

Considering the emissions and socio-economic development of these scenarios, S2, S4, and S5 represent satisfied outputs. Under these three scenarios, low-carbon strategies, including a decrease of carbon intensity, improvement of energy efficiency, and adjustment of industry structure, will be performed. Meanwhile, the economy, population, and urbanization will develop at a high or medium speed. 
In terms of industry structure, there is a distinction among Beijing, Tianjin, and Hebei: the energy-intensity industries in Beijing will be less concentrating in car assembly. At the same time, more high-tech and cultural industries will be built to increase its ration of the third industry; Tianjin's governments will focus on the non-agricultural processing industry, especially the electronic information industry and advanced manufacture. Under the continuation of the mining industry and electricity generating, Hebei will strictly control the total expansion of industries with extensive energy consumption and emissions.

Decreasing the ratio of coal to total energy consumption offers an important tool to low-carbon emissions. First, the IGCC will be improved continually based on the existing appliance in Tianjin. In addition to scaling up the use of natural gas, local government will also actively accelerate the development of hydro, wind, solar, and nuclear power in a safe and efficient manner. Local governments should also proactively develop geothermal, bio, and maritime energy. Besides, the expansion of distributed energy would provide residents with a convenient and effective electricity manner.

Controlling emissions from building and transportation sectors is very important support for low-carbon targets. In future decades, local governments will gradually promote the share of green buildings in newly built building of cities, which means the application of non-fossil energy in daily life and acceptable energy-saving construction, such as advanced ventilation systems and low-cost and efficient solar PV buildings. For transportation, more incentive measures will be promoted and optimized to establish a green transportation system. For example, the share of public transport with green fuels will be improved and measures for the convenience of pedestrians and bicycles will become enriched. Moreover, with technological innovation, urban rail transport will first be popularized, followed by hybrid vehicles, and then fuel cell vehicles as well as efficient pure electric vehicles.

As for technology, more improvement will be carried out about power industry and steel industry to reduce the energy consumption and $\mathrm{CO}_{2}$ emissions. For power industry, IGCC will be scaled up-in Tianjin's power plant; large-scale offshore wind power generation will also be feasible in Tianjin because of its location by the sea; and more new tech, such as low cost CCS, solar nanotechnology photovoltaic, and large-scale electricity storage systems for intermittent power supply will be gradually exploited after 2030 in Hebei province. As for the steel industry, pulverized coal-injection technology, residual heat and pressure recovery, and smelting reduction technologies including COREX, FINEX, and coal moisture control are becoming popular in the Beijing-Tianjin-Hebei region; local governments will try to introduce and spread SCOPE21 coking technology to improve production efficiency; and the investment in low-cost CCS technology will increase and be applied after 2030.

\section{Conclusions}

In this study, the extended STIRPAT model was established as a foundation to research the future footprint of $\mathrm{CO}_{2}$ emissions in the Beijing-Tianjin-Hebei region. The squared term of GDP per capita, population, technological level, urbanization level, coal consumption to total energy consumption, and the secondary industry share of GDP were innovatively applied together as driven factors of emissions in this paper. In addition, eight different scenarios were set to seek the maximum $\mathrm{CO}_{2}$ emissions. According these scenarios, we find that the control about energy efficiency, energy construction, industry construction, and technological level in future decades were significant for the Beijing-Tianjin-Hebei region to ensure low carbon emissions. The analysis of scenarios drawn by this study is useful for the local government to design relative strategies. Although with large pressure the $\mathrm{CO}_{2}$ emissions would turn to decrease before 2050 in the Beijing-Tianjin-Hebei region, and there would be at least three reasonable development models where the economy as well as social level would develop with a relative high speed. The study also proposed a series of solutions to improve the efficiency of energy and resource use, optimize industry construction and technological level, and reduce emissions and mitigate the adverse impact of climate change.

This paper gives us a direction about low-carbon development. However, many aspects are worthy of further study to provide local governments with more useful advice. The government would pay more attention to build an energy-saving and low-carbon society with human development, sustainable economic development, and stable urbanization.

\section{Acknowledgements}

This work is supported by the Fundamental Research Funds for the Central Universities (No. 12ZX12).

\section{References}

1. IEA. Energy technology perspectives 2012. International Energy Agency; 32-40, Paris, 2012.

2. United Nations Development Program (UNDP). China and a sustainable future: towards a low carbon economy and society. China human development report; 47-73, China, 2009.

3. EIA (US Energy Information Administration).Total Carbon Dioxide Emissions from the Consumption of Energy; The U.S., $\quad$ 2011. $<$ http://tonto.eia.doe.gov/cfapps/ipdbproject/ IEDIndex3.cfm?tid $=90 \&$ pid $=44 \& \quad$ aid $=8 \mathrm{~S}>$ [accessed 11.06.15].

4. Carbon dioxide information analysis center (CDIAC). 2013 Global Carbon Project; The U.S., 2013. <http://cdiac. ornl. gov/GCP/carbonbudget $/ 2013 />$ [accessed 12.06.15].

5. DIETZ T., ROSA E.A. Rethinking the environmental impacts of population. Affluence and technology, Hum. Ecolo. Rev. 1, 277, 1994. 
6. DIETZ T., ROSA E.A. Effects of population and affluence on $\mathrm{CO}_{2}$ emissions. Proc. Nat.Acad.Sci.U.S.A, 94 (1), 175, 1997.

7. WOLD S., ALBANO C., DUNN W.J., ESBENSEN K., HELlBerG S., Johansson E., Sjöström M. Pattern recognition: finding and using regularities in multivariate data. Food Research and Data Analysis. Applied Science Publishers, 176, 1983.

8. HOERL A.E., KENNARD R.W. Ridge Regression: Biased Estimation for Nonorthogonal Problems. Technometrics, 12 (1) $55,1970$.

9. KENNY T., GRAY N.F. Comparative performance of six carbon foot print models for use in Ireland. Environmental Impact Assessment Review, 29 (1), 1, 2009.

10. SUN J.W. The nature of $\mathrm{CO}_{2}$ emission Kuznets Curve. Energy Policy, 27 (12), 691, 1999.

11. MENG M., NIU, D.X. Modeling $\mathrm{CO}_{2}$ emissions from fossil fuel combustion using the logistic equation. Energy, 36 (5), 3355, 2011

12. WANG S. J., FANG C. L., GUAN X. L., PANG B., MA H. Urbanisation, energy consumption, and carbon dioxide emissions in China: A panel data analysis of China's provinces. Applied Energy; 136 (C), 738, 2014.

13. Research Group of energy and carbon emissions in China 2050. China energy and carbon emission report, 753, Beijing, 2009.

14. WANG T., WATSON J. China's energy transition: pathways for low carbon development. United Kingdom:University of Sussex, $2009<\mathrm{http} / / /$ www.sussex.ac.uk/ $>$ [accessed 12.05.15]

15. ZHOU N., FRIDLEY D., MCNEIL M.A., KHANNA N., KE J., LEVINE M.D. China's energy and carbon emissions outlook to 2050. CA: Lawrence Berkeley National Laboratory, 2012.

16. McKinsey\&Company. Energy and environment technology options to achieve sustainable development. China's Green Revolution, 2009. <http://www.mckinsey.com/locations/ chinas implified/ mckonchina/reports/ china green revolution_report_cn.pdf $>$ [accessed 12.05.15]

17. EHRLICH P., HOLDREN J. Impact of population growth. Science, 171 (45), 1212, 1971.

18. WAGGONER P.E., AUSUBEL J.H. A framework for sustainability science: A renovated IPAT identity. Proc. Nat. Acad. Sci. USA, 12 (6), 7860, 2002.

19. SONG J., SONG Q., ZHANG D., LU Y., LUANET L. Study on Influencing Factors of Carbon Emissions from Energy Consumption of Shandong Province of China from 1995 to 2012. The Scientific World Journal, 2014 (1), 56, 2014

20. ZHANG C., LIN Y. Panel estimation for urbanization, energy consumption and $\mathrm{CO}_{2}$ emissions: A regional analysis in China. Energy Policy, 49, 488, 2012.

21. YORK R., ROSA E., DIETZ T. STIRPAT, IPAT, and ImPACT: analytic tools for unpacking the driving forces of environmental impacts. Ecological Economics, 46, 351, 2003.

22. WANG Z., YIN F., ZHANG Y., ZHANG X. An empirical research on the influencing factors of regional $\mathrm{CO}_{2}$ emissions:
Evidence from Beijing city, China. Energy Policy, 100 (4), 277, 2012

23. LIN S., ZHAO D., MARINOVA D. Analysis of the environmental impact of China based on STIRPAT model. Environ. Impact Assess, 29 (6), 341, 2009.

24. HESSAMI M., GACHON P., OUARDA T., ST-HILAIRE A. Automated regression based statistical downscaling tool. Environmental Modelling and Software, 23 (6), 813, 2008.

25. YAN-FU L., MIN X., THONG-NGEE Goh. Adaptive ridge regression system for software cost estimating on multicollinear datasets. The Journal of Systems and Software, 83 (11), 2332, 2010

26. WANG P., WU W., ZHU B., WEI Y. Examining the impact factors of energy-related $\mathrm{CO}_{2}$ emissions using the STIRPAT model in Guangdong Province, China. Applied Energy, 106 (11), 65, 2013.

27. DINDA S. Environmental Kuznets Curve hypothesis: a survey. Ecological Economics, 49 (4), 431, 2004.

28. STERN D. The rise and fall of the Environmental Kuznets Curve. World Development, 32 (8), 1419, 2004.

29. GONG G., WANG D., CHUN L. Research on carbon emissions of energy in Shanghai. Chinese population Resources and Environment, 20 (2), 103, 2010.

30. AKDENIZ F., GÜZIN Y., ALAN T.K.W. The moments of the operational almost unbiased ridge regression estimator. Applied Mathematics and Computation, 153 (3), 673, 2004.

31. NGO S.H., KEMÉNY S., DEÁK A. Performance of the ridge regression method as applied to complex linear and nonlinear models. Chemometrics and Intelligent Laboratory Systems, 67 (1), 69, 2003.

32. JEFFERY R., RUHE M., WIECZOREK I. A comparative study of two software development cost modeling techniques using multi-organizational and company-specific data. Information and Software Technology, 42 (14),1009, 2000.

33. KUTNER M.H., NACHTSHEIM C.J., NETER J., LI W. Applied Linear Statistical Models, 5th ed. McGraw-Hill, 408, Londo, 2005.

34. BELSLEY D.A., Condition Diagnostics Collinearity and Weak Data in Regression. Wiley, New York; 1991.

35. NBSC (National Bureau of Statistics of China). China Statistics Yearbook of 2013. China Statistics Press; 78-83, China, 2013.

36. ZANG Y., LI S., SUN Y., CHEN Y., ZHANG M. The trends of population and Regional Carrying Capacity in the BeijingTianjin-Hebei region, Journal of Academic Frontier, 2, 169, 2013.

37. XU X. China's Economic Growth in Future and Prospect of Its International Economic Position. Economic Research Journal, 3 (3), 27, 2002.

38. IMF. Uneven Growth: Short-Term and Long-Term Factors; USA, 2015. <http://www.imf.org/ External/pubs/ft/weo /2015/01/index.htm $>$ [accessed 12.06.15].

39. MINX G., BAIOCCHI G. P., PETERS C. L., WEBER D., GUAN K., HUBACEK A. "Carbonizing Dragon": China's fast growing $\mathrm{CO}_{2}$ emissions revisited. Environ. Sci. Technol, 45 (21), 9144, 2011. 